\title{
PERCEPÇÕES E ANÁLISES DA GESTÃO DE RISCOS NO ARQUIVO DA PRÓ-REITORIA DE GESTÃO DE PESSOAS DA UNIVERSIDADE FEDERAL DO CEARÁ
}

\section{PERCEPTIONS AND ANALYSIS OF RISK MANAGEMENT IN THE ARCHIVE OF THE PEOPLE'S MANAGEMENT OFFICE THE FEDERAL UNIVERSITY OF CEARÁ}

\author{
Italo Teixeira Chaves (15) \\ Universidade Federal do Ceará \\ Luciano Pereira dos Santos Cavalcante \\ Universidade Federal do Ceará
}

\begin{abstract}
RESUMO
O presente artigo levanta discussões teóricas e práticas relacionadas à gestão e ao gerenciamento de riscos em unidades de informação, com o foco no arquivo da Pró-Reitoria de Gestão de Pessoas da Universidade Federal do Ceará. Tem como objetivo investigar as percepções dos colaboradores do arquivo sobre a temática gestão de riscos, além de realizar a identificação e análise de riscos a partir do Método Mosler na referida unidade de informação. Para isso, fundamenta-se metodologicamente na pesquisa de campo e exploratória, com abordagem qualitativa, utilizando-se de formulários eletrônicos para coleta de dados. Apresenta como resultado as percepções dos colaboradores do arquivo, onde percebeu-se que a gestão de riscos ainda é um aspecto pouco conhecido e trabalhado nesta unidade de informação. Identificaram-se cinco riscos potenciais, que vêm sendo observados e tratados pela equipe gestora, o que resultou em classes de riscos pequenos ou muito pequenos para o arquivo, sendo riscos controláveis, embora haja necessidade de um plano de gerenciamento de riscos. Conclui-se que a gestão e gerenciamento de riscos são aspectos importantes nas unidades de informação, deste modo, os cursos de graduação e as unidades de informação precisam fornecer capacitações para o fortalecimento de ações frente a presença de riscos.
\end{abstract}

Palavras-Chave: Gestão de riscos. Gerenciamento de riscos. Análise de riscos. Método Mosler.

\begin{abstract}
This article raise theoretical and practical discussions related to risk manangement and manangement in information units with a focus on the archive of the People's Manangement Office the Federal University of Ceará. It alms to investigate the perceptions of archive's employees on the theme of risk manangement, in addition to carrying out of the risk identification and analysis in the Mosler methodology in that information unit. For this, it is methologically based on field and exploratory research with a qualitative approach, using electronic forms for data collection. As a result, it presents the perceptions of the archives' employees, where it was realized that risk management is still a little-known aspect and worked on in this information unit. Five potential risks were identified, which have been observed and dealt with by the management team, which resulted in small or very small risks for the file. It is concluded that risk management and risk management are important aspects in the information units, showing little knowledge among employees. Thus, within the analyzes it was shown that the risks within the information units are presented in a manageable manner, even though there is no risk management protocol in the division, however it needs more effective actions in the presence of potential risks.
\end{abstract}

Keywords: Risk management. Enterprise Risk Management. Risk analysis. Mosler Methodology. 


\section{INTRODUÇÃO}

No panorama geral da gestão, independentemente da atividade que seja executada ou da área de atuação, o risco se encontra presente em qualquer contexto ou lugar. Desse modo, o gerenciamento de riscos vem a ser uma ferramenta administrativa que busca identificar, prevenir e mitigar determinadas eventualidades que podem acarretar contratempos ou acontecimentos indesejados em determinados ambientes. Assim, discutir sobre gerenciamento de riscos pode ser considerado um mecanismo de controle na maneira como a gestão é aplicada, no sentido de minimizar previamente os efeitos advindos da exposição dos riscos.

A epistemologia do conceito acerca de risco pode ser interpretada de maneiras diversas. Para Cocurullo (2003, p. 71) “a concepção de risco pode ser atribuída quando surgem determinadas situações que impeçam atingir metas organizacionais ou a ausência destas situações que possam limitar ou procrastinar os objetivos na perspectiva de alcançar os objetivos desejados. No entanto, ainda segundo Cocurullo (2003), situações que podem gerar riscos não se limitam ao prejuízo no campo financeiro, pois no mundo corporativo os objetivos são estabelecidos em diversos aspectos que devem ser alcançados pelos setores que compõem a organização. Percebe-se que o risco é toda inconformidade com os objetivos anteriormente traçados pela administração da instituição.

Conforme Brito (2002, p. 03) o risco compreende “a possibilidade de um evento, que afeta negativamente o ato de acontecer". Este conceito foca o risco sob o aspecto negativo de seus impactos. Neste mesmo sentido, de acordo com Santos (2002, p. 23), "risco é o grau de incerteza em relação à possibilidade de ocorrência de um determinado evento, o que, em caso afirmativo, redundará em prejuízos". Desse modo, risco é a possibilidade de perda decorrente de um determinado evento. Para estes autores o risco pode estar relacionado a eventualidades e contratempos no ambiente organizacional com consequências negativas ao planejamento estratégico e ao resultado das metas e objetivos traçados.

Dito isto, destaca-se a tendência atual no processo de gerenciamento dos riscos na busca pela minimização dos seus impactos nos processos e valores das organizações, pois constata-se uma atividade voltada a agregar valor ao negócio, proporcionando benefícios qualitativos e quantitativos. Ao proteger-se das incertezas do mercado e dos ambientes internos e externos que interagem com a organização, de certo modo, busca-se garantir determinado grau de certeza na aferição e garantia de seus resultados.

Posto isso, o presente estudo objetiva investigar aspectos relacionados à gestão de riscos, tendo como locus da pesquisa o arquivo da Pró-Reitoria de Gestão de Pessoas (PROGEP), da 
Universidade Federal do Ceará (UFC). A partir de uma pesquisa exploratória, com abordagem qualitativa, apresenta-se as percepções dos colaboradores da organização a respeito do gerenciamento de risco em um arquivo institucional. Tais dados foram coletados a partir de um formulário eletrônico, onde teve-se a resposta de todos os colaboradores, sendo 12 servidores e 3 bolsistas. Além da identificação e análise de risco a partir do Método Mosler.

A relevância deste estudo está no sentido de fomentar uma contribuição teórica a partir de discussões sobre a temática gestão e gerenciamento de riscos no âmbito das unidades de informação, pois segundo apontamentos de Nobre e Souza (2018), existem poucas discussões sobre gestão de riscos voltadas às unidades de informação. Além disso, apresenta-se uma contribuição empírica a partir das análises sobre as percepções da gestão de risco no arquivo da PROGEP-UFC, as quais colocam em evidência os riscos presentes no arquivo e os devidos tratamentos. Busca-se explicitar como a gestão de riscos é utilizada, sua importância, bem como os elementos que condicionam para que esse instrumento seja utilizado de maneira adequada dentro da unidade de informação de forma a mitigar situações que por ventura, se apresentem como indesejáveis.

\section{GESTÃO DE RISCOS: CONCEITOS, ABORDAGENS E APLICABILIDADES EM UNIDADES DE INFORMAÇÃO}

O termo unidades de informação faz referências às organizações como bibliotecas, arquivos, museus, centros e núcleos de documentação, dentre outros, que tem como objetivo central o oferecimento de produtos e serviços informacionais para atender as necessidades dos seus usuários (BELLUZZO, 2007 apud MACEDO; ORTEGA, 2019). Para além do atendimento ao usuário, é preciso ter atenção também para os riscos que envolvem o acervo, de modo a evitar possíveis perdas nas unidades.

A palavra risco está relacionada a diversos significados na língua portuguesa, como algo que pode acontecer, uma possibilidade ou uma situação a ser evitada. É uma palavra que pode estar presente em pesquisas de diversas áreas do conhecimento, à citar algumas: administração, economia, saúde, ciências sociais, biblioteconomia, engenharia, dentre outras. Deste modo, pode-se entender que os estudos relativos ao risco querem "alertar para as consequências futuras negativas de uma variedade praticamente ilimitada de fenômenos e processos." (BRÜSEKE, 2007, p. 71).

A temática envolvendo os riscos em diversos contextos torna-se ainda mais complexa ao considerar-se o mundo contemporâneo, onde a globalização, a tecnologia, a produção e organização do conhecimento são fatores determinantes para o sucesso das instituições. Nesses meios, o 
documento tem um papel fundamental, pois a partir dele é possível gerir, criar, transferir e utilizar o conhecimento como algo importante para o desenvolvimento organizacional, como também nas tomadas de decisões, além de servir como algo que potencialize a eficiência organizacional, o que se torna indispensável em meio a competitividade (PRADO et al., 2017; SILVA; ARAÚJO; CAMPELLO, 2020).

Diante da tamanha responsabilidade e a importância relacionadas à gestão e disponibilização de informação, é preciso que os ambientes responsáveis por este produto (a informação), sejam unidades de informação como os arquivos, bibliotecas, museus ou centros de documentação, que compreendam a necessidade de trabalhar os riscos que são inerentes à esses ambientes e avaliem as possíveis formas de evitá-lo, ou mesmo como conduzir em uma situação de catástrofe em curso. Lima e Freire (2019) alertam para os riscos nas unidades de informação, ressaltando fatores como catástrofes naturais, processos de degradação documental ou mesmo a ação humana.

Os aspectos citados por Lima e Freire (2019) colocam em evidência a carência do gerenciamento de riscos nas unidades de informação, uma vez que os riscos já são de conhecimento dos gestores, porém, requerem um planejamento para lidar com essas problemáticas que podem comprometer os processos de arquivamento e a proteção dos dados institucionais. Esclarece-se, portanto, que a gestão de riscos envolve a manutenção da estabilidade dos resultados das organizações, estando relacionado com os conhecimentos, os métodos e os processos organizados para reduzir eventuais prejuízos e aumentar os benefícios na concretização dos objetivos estratégicos (BARALDI, 2005).

Segundo Salles Júnior (2006, p. 28), o gerenciamento de riscos compreende “o processo de identificação, análise, desenvolvimento de respostas e monitoramento dos riscos em projetos, com o objetivo de diminuir a probabilidade e o impacto de eventos negativos e de aumentar a probabilidade de eventos positivos". Logo, ao se calcular esse cenário aplicado às unidades de informação, precisa-se levar em consideração os materiais que estas dispõem, como livros, arquivos, mapas, além de outros e quais cuidados são necessários. Além de também reconhecer questões ambientais internas e externas que podem configurar risco de alguma natureza, ou mesmo sobre os conhecimentos do corpo funcional em lidar com os materiais, visto que a ação humana também pode configurar um fator de risco.

Nesse sentido, para que a gestão de riscos possa ser efetivada de forma concreta dentro das unidades de informação e um planejamento de gerenciamento de riscos seja construído, é 
importante compreender e classificar os riscos potenciais que podem ameaçar as unidades. Salientase que essa identificação dos riscos deve ocorrer de uma maneira sistêmica, abordando-se a questão a partir da identificação das fontes de riscos e, no caso particular das UI, dos principais agentes de deterioração, o que pode afetar o acervo e os interesses (NOBRE; SOUZA, 2018, p. 29).

Essa classificação de riscos precisa ser realizada individualmente por cada unidade de informação, onde-se compreenda, de modo integrativo, as possibilidades, desafios e potencialidades no tocante do gerenciamento de riscos, de maneira a não só compreender o que pode afetar de modo negativo a unidade, como também o que fazer para evitar.

Algumas instituições responsáveis pelo patrimônio documental, tais como a Biblioteca e o Arquivo Nacional possuem um planejamento de gerenciamento de riscos, documento institucionalizado que orienta na tomada de decisões para lidar com os riscos nas respectivas instituições. Esse tipo de gestão está também relacionado como uma maneira de proporcionar conservação preventiva dos acervos, pois é uma forma de elencar prioridades e destinar recursos para o patrimônio documental (SILVA; NASCIMENTO, 2015).

Dias (2018) enfatiza a importância dos arquivos no que diz respeito a guarda de documentos, além de relacionar esta importância com fatores sociais e memorialísticos. Nesse sentido, O Arquivo Nacional, que tem como o objetivo o tratamento técnico e preservação do patrimônio documental nacional, elaborou um planejamento de gerenciamento de risco. Este plano desenvolveu-se em quatro estágios de aplicação, sendo eles: Planejamento e estabelecimento do contexto, Identificação, análise e priorização de riscos, Tratamento de riscos e Comunicação e continuidade (PEREIRA et al., 2019).

A Biblioteca Nacional pontua que seu plano de gerenciamento de riscos envolve todos os níveis e setores, buscando cooperação e integração entre os setores, além de ser um documento permanente para promover a gestão da instituição. É um documento importante usado para prevenir e contra-atacar eventuais riscos a partir do uso de recursos próprios e permanentes da instituição, o que garante também um grau de sustentabilidade ao planejamento (SPINELLI; PEDERSOLI JÚNIOR, 2010).

Spinelli e Pedersoli Júnior (2010) apresentam em seu documento dez agentes de deterioração os quais os gestores devem estar atentos para os riscos que eles podem ocasionar aos acervos e as unidades de informação. Explicam que à compreensão desses dez fatores "facilitam a identificação de riscos a partir da consideração de dez agentes de deterioração, os quais, ao 
interagirem fisicamente com o patrimônio da instituição, podem causar graves danos e perdas, representando, por isso, situações de perigo." (SPINELLI; PEDERSOLI JÚNIOR, 2010, p. 25).

Figura 1 - Dez agentes de deterioração

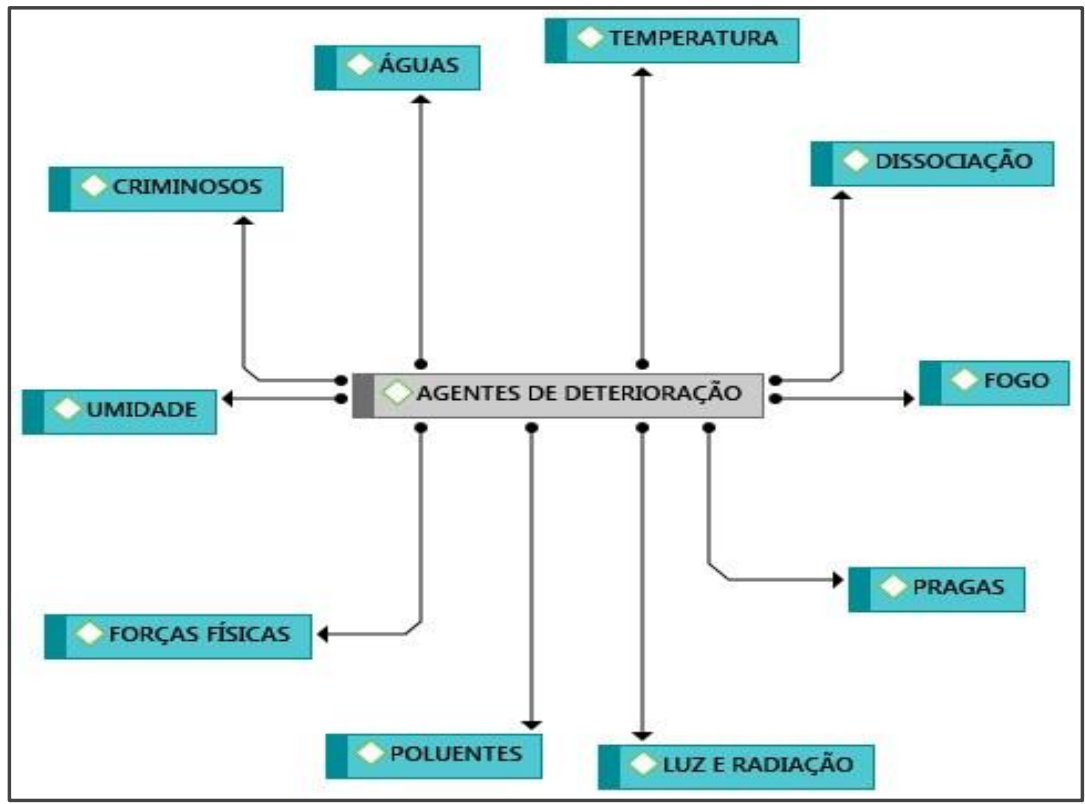

Fonte: Elaborado pelos autores (2020) a partir de Spinelli e Pedersoli Júnior (2010).

Nessas perspectivas, é preciso que além de se identificar os riscos, elabore-se um planejamento ou política de gerenciamento de riscos para a Unidade de Informação. Conforme a Associação Brasileira de Normas Técnicas (2009), esse tipo de instrumento deve conter em seu escopo de forma clara e objetiva, a justificativa, as responsabilidades, a disponibilização de recursos e avaliação de desempenho da própria política para gestão de riscos.

Ainda nesse sentido, é imprescindível a adoção dessas práticas no intuito de sistematizar os processos no tocante aos riscos, destacando-se metodologias que tenham o objetivo de contribuir e direcionar na prevenção de riscos. Com isso, basear-se em tais procedimentos metodológicos já existentes, é uma forma de implementar, com praticidade e objetividade a gestão e o gerenciamento de riscos em unidades de informação, adaptando-os para a realidade da unidade.

Um dos métodos bastante usados em ambientes corporativos e que também será o principal deste trabalho é o de Mosler. “O Método de Mosler é uma forma de gestão de riscos corporativos que acompanha a evolução dos riscos de maneira geral." (VENEZIA; ONO, 2013, p. 91). Deste modo, é algo que tem possibilidade para aplicação em ambientes arquivísticos, uma vez que o método compreende riscos diversos que estão presentes nas unidades de informação. 
Brasiliano (2005) explica a respeito do Método Mosler, onde são utilizadas seis escalas, com variância entre 1 e 5 para mensuração do risco. As escalas estão relacionadas a função (f), substituição (s), profundidade (p), extensão (e), probabilidade (pb) e impacto financeiro (if) do risco. Este método observa fatores qualitativos e quantitativos e reconhece a volatilidade dos riscos, isto é, um risco que não estava em evidência pode vir à tona e isso acarretará mudanças na escala e, consequentemente, na gravidade do risco.

A resposta aos riscos, por sua vez, deve estar institucionalizada por meio de uma política ou planejamento de gestão de riscos. Esse documento é o responsável por auxiliar na tomada de decisões no caso de acontecer ou mesmo de prevenir possíveis riscos nas unidades de informação.

O plano de gerenciamento de riscos deve ser totalmente integrado no sistema de gerenciamento maior da organização. A comunicação é um fator importante neste momento porque este é um momento em que mudanças concretas ocorrem na organização e precisam ser claramente compreendidas e suportadas em todos os níveis da unidade de informação (LIMA; FREIRE, 2019).

\section{PERCURSOS METODOLÓGICOS E OPERACIONAIS}

Os procedimentos metodológicos que norteiam esta pesquisa, iniciam-se a partir de uma pesquisa bibliográfica e documental para compreender o estado da arte das temáticas estudadas, sendo elas: gestão de unidades de informação, gestão de riscos e gerenciamento de riscos. Gil (2010) pontua a vantagem da pesquisa bibliográfica, uma vez que a partir dela os pesquisadores poderão adquirir conhecimentos concisos a respeito da temática estudada. Esse aspecto tem sua relevância ainda justificada pelas considerações de Nobre e Souza (2018), ao pontuarem a pouca literatura científica sobre a temática no que concerne ao gerenciamento de risco nas unidades de informação.

Após isso, a pesquisa configura-se enquanto exploratória e de campo, onde têm-se como locus de estudo o Arquivo da Pró-reitoria de Gestão de Pessoas da Universidade Federal do Ceará. Marconi e Lakatos (2010) explicam que nesse tipo de pesquisa procura-se conhecer-se o problema estudado, para o levantamento de hipóteses e descoberta de novos fenômenos. Assim sendo, a pesquisa de campo consistiu-se em dois momentos, sendo o primeiro deles uma visita técnica dos pesquisadores para conhecer e ambientar-se com o espaço físico do arquivo, com o objetivo de identificar e avaliar possíveis riscos nesta unidade de informação a partir do Método Mosler.

O segundo momento do campo, consistiu na aplicação de um formulário onde os servidores e bolsistas alocados no arquivo puderam responder a respeito dos seus próprios conhecimentos 
sobre o gerenciamento de riscos. O formulário teve o total de 15 respondentes, sendo 12 servidores e 3 bolsistas, todos estes de diversas áreas do conhecimento. O formulário era composto por seis perguntas, todas elas de múltipla escolha.

A partir disso, realiza-se a análise de dados por um perspectiva qualitativa de modo a compreender as percepções e conhecimento dos colaboradores sobre a gestão de riscos, tanto no que diz respeito às práticas aprendidas durante o trabalho no arquivo como na graduação, além disso, analisou-se um total de cinco risco, utilizando-se o Método Mosler, para conhecer a natureza dos riscos (de baixo a elevado) bem como o impacto financeiro no arquivo.

\section{RESULTADOS E DISCUSSÕES}

\subsection{Percepções sobre gestão de riscos}

Na unidade de informação que consta o objeto de estudo em questão, foi aplicado um questionário com perguntas simples e objetivas com intuito de compreender e entender a respeito das percepções e conhecimento dos colaboradores do arquivo estudado. Eram um total de 6 perguntas objetivas, onde as três primeiras são apresentadas na tabela 1.

Tabela 1 - Conhecimento sobre gestão de risco

\begin{tabular}{lcc}
\hline \multicolumn{1}{c|}{ Perguntas } & Sim & Não \\
\hline $\begin{array}{l}\text { 1. Você conhece ou já estudou a cerca de } \\
\text { gestão de riscos? }\end{array}$ & $\begin{array}{c}12 \\
(80 \%)\end{array}$ \\
\hline 2. Durante suas atividades no Arquivo, você & 3 \\
já recebeu algum tipo de treinamento sobre gestão de & $(20 \%)$ \\
riscos? & & $(80 \%)$ \\
\hline 3. Em algum momento durante sua & 5 & 12 \\
graduação foi abordado o conteúdo acerca de gestão \\
de riscos?
\end{tabular}

Fonte: Dados da pesquisa (2019).

Dessa forma o referido questionário estava estruturado de forma que a primeira pergunta estava relacionada ao estudo dos colaboradores tocante à gestão de riscos. A partir dos dados coletados, percebeu-se que a maioria já estudou em algum momento algo relacionado a essa temática, logo, possuem conhecimentos relacionados a esse assunto. Silva e Nascimento (2015, p. 28) pontuam que "o processo de gestão de riscos deve ser absorvido nas práticas, bem como na cultura 
da instituição." , deste modo, torna-se imprescindível que os colaboradores tenham estudado algo sobre o assunto para sua efetiva aplicação.

A pergunta dois esteve relacionada aos possíveis treinamentos sobre o gerenciamento de riscos oferecidos na própria unidade de informação ou a partir dela. Percebeu-se de início que somente $20 \%(\mathrm{~N}=3)$ teve algum treinamento nessa área, o que pode resultar em dificuldades para a implementação da gestão risco, visto que é necessário que todo o corpo funcional compreenda as nuances desse tipo de gestão e saibam agir a partir do surgimento de riscos, onde esses aspectos podem demonstrar que a, referida unidade de informação necessita deter uma maior propagação dessa ferramenta para os/as outros/as colaboradores para que haja uma efetividade maior no processo de mitigação de riscos.

Destaca-se que a atitude perante o risco, sendo este o processo de avaliar, reter, ou afastar-se do risco (ABNT, 2009) ocorrerá mediante treinamento. Logo, é uma necessidade para que as unidades de informação possam fornecer subsídios para capacitar o seu corpo funcional, sobretudo quando se trata do gerenciamento de riscos, que podem proporcionar o cumprimento de metas estratégicas (PRADO et al., 2017).

Ainda relacionado ao treinamento e conhecimento da gestão de riscos, com o enfoque na graduação, notou-se que a maioria dos respondentes não tiveram disciplinas que abordassem essa temática. Tal fator torna-se preocupante ao passo que também reflete no ambiente estudado o não preparo para lidar com os riscos. Nessa situação, Hollós e Pedersoli Jr. (2009) afirmam que para além da consulta e comunicação, é necessário também uma abordagem interdisciplinar para o sucesso e eficácia da gestão de riscos.

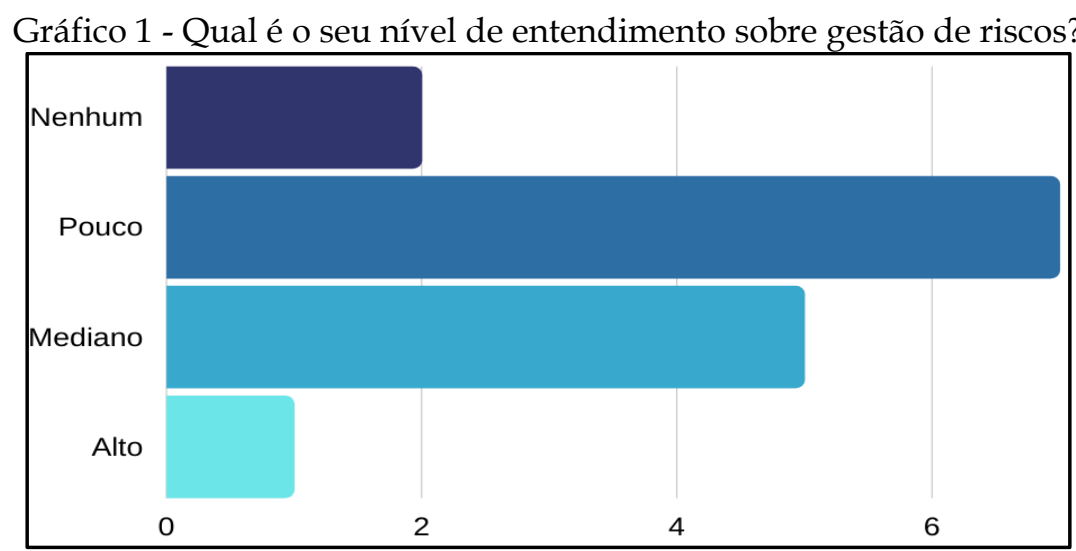

Fonte: Dados da pesquisa (2019).

Percebeu-se a partir do exposto no gráfico 1 que o conhecimento dos funcionários do arquivo sobre gestão de riscos tem considerada variedade nas respostas. Constatou-se que aproximadamente 
$60 \%(\mathrm{~N}=9)$ dos colaboradores do arquivo tem pouco ou nenhum conhecimento sobre esse tema, seguido de $33.3 \%$ com conhecimento mediado $(\mathrm{N}=5)$ e $6.6 \%(\mathrm{~N}=1)$ com alto conhecimento.

Essa variância nos resultados coletados demonstra novamente a necessidade de capacitar os funcionários para lidar com o gerenciamento de riscos, de modo a aplicar os conhecimentos adquiridos para combater e lidar com as ameaças presentes no arquivo. A partir disso, apresentouse o gráfico 2 onde pôde-se averiguar os canais de comunicação usados para relatar a existência de algum risco no arquivo.

Gráfico 2 - Mecanismos de comunicação

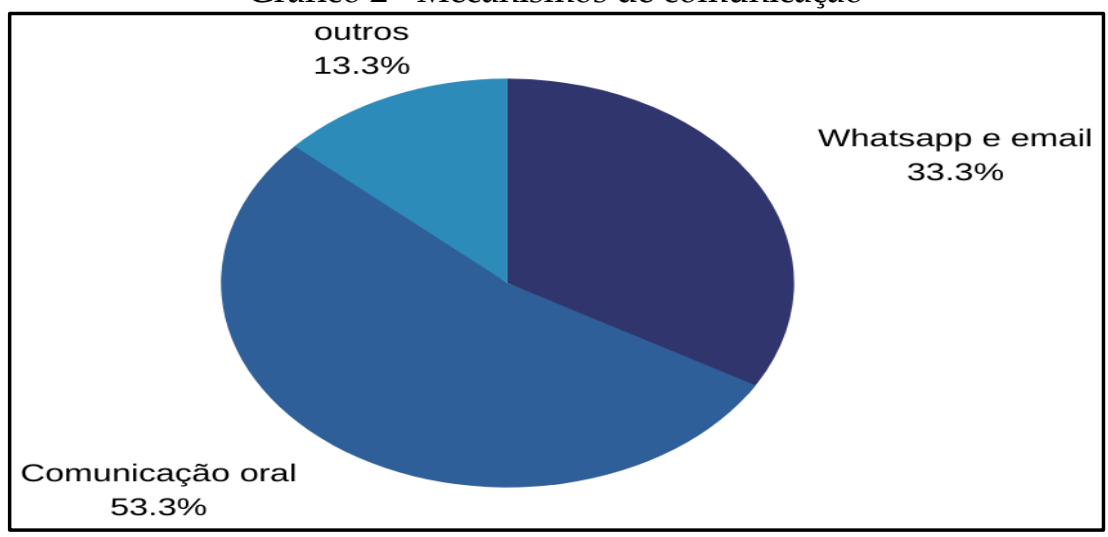

Fonte: Dados da pesquisa (2019).

A comunicação é um aspecto importante para a efetivação do gerenciamento de riscos nas unidades de informação. É por meio da identificação e comunicação do risco que serão realizadas ações para contingenciar danos no acervo documental de maneira mais efetiva. Nesse sentido, percebeu-se que a principal forma de comunicação no arquivo estudado foi a comunicação oral, isto é, uma comunicação imediata para o gestor da unidade, alertando-o sobre possível acontecimento, onde isso acontece de maneira contínua, ou seja, no momento em que o trabalho está ocorrendo. Em segundo lugar, segue-se a comunicação por whatsapp ou e-mail e em terceiro, outros, onde entram possibilidades de comunicação como ligações, enaltecendo que o trabalho de gerenciar os riscos e sua disseminação acontecem de maneira pontual e gradativa, não havendo um conhecimento institucionalizado.

Gráfico 3 - Importância e periodicidade para realizar gestão de riscos

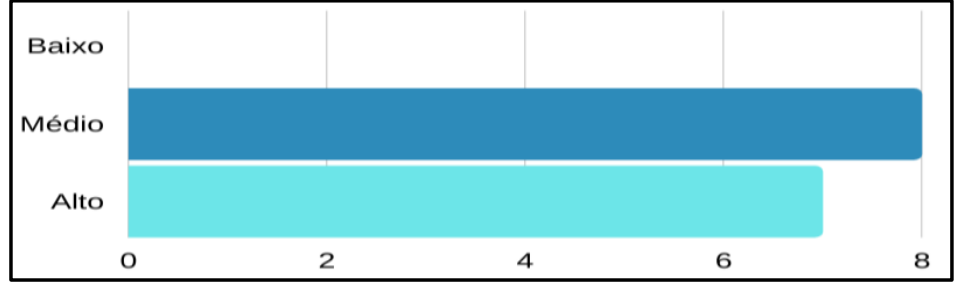

Fonte: Dados da pesquisa (2019). 
Como forma de concluir a discussão a respeito das percepções sobre gestão de riscos, identificou-se qual a importância e a periodicidade para se realizar a gestão de riscos. Obteve-se como respostas que $53 \%$ consideram de importância mediana $(N=8)$ e que $47 \%$ consideram esse nível como alto (N=7). Esses resultados são satisfatórios uma vez que demonstram que há certa compreensão sobre a importância de desenvolver uma gestão de riscos eficaz no arquivo, que deem embasamentos para proteção documental, arquitetônica e estrutural do ambiente.

\subsection{Análise de riscos à luz do Método Mosler}

O Método Mosler é uma proposta metodológica baseada no impacto financeiro cujo tem critérios para identificação dos riscos em uma escala de valores. É um método que viabiliza o acompanhamento dos riscos pela operacionalização de seis critérios e seus valores são predefinidos para classificar os diferentes riscos. Brasiliano (2005) apresenta os seis critérios da metodologia de Mosler, que são:

A. Função (f) que estima os danos que podem ocorrer e alterar as atividades da organização, sendo representado de 5 para muito gravemente à 1 para muito levemente.

B. Substituição (s), que estima os danos que podem resultar em uma difícil substituição, representado por 5 para muito dificilmente à 1 para muito facilmente.

C. Profundidade (p) que mede as consequências resultantes da ocorrência do risco na organização. É medido com 5 para muito grave à 1 para muito leve.

D. Extensão (e) a qual mede o alcance que um risco acarretaria, com as seguintes escalas e pontuações, sendo medido com 5 para caráter internacional à 1 para individual.

E. Probabilidade $(\mathrm{Pb})$ que indica a chance do risco acontecer. Esse critério é medido como muito alto (5) à muito baixo (1).

F. Impacto financeiro (If) que mensura as perdas no acontecimento do risco. É medido como 5 para muito alta à 1 para muito baixa.

Foram encontrados cinco riscos em potencial no arquivo da PROGEP e para melhor ilustração, foi elaborada uma tabela (tabela 2) onde são apresentados os riscos, uma análise a partir dos critérios do Método Mosler. Considera-se ainda a importância do sucesso (I=fxs), os danos causados $(\mathrm{D}=\mathrm{pxe})$ para identificar a magnitude do risco $(\mathrm{M}=\mathrm{I}+\mathrm{D})$. Por fim, calcula-se a perda esperada ( $\mathrm{Pe}=\mathrm{PbxIf})$ para compreender o impacto do risco $(\mathrm{Er}=\mathrm{MxPe})$. Os riscos podem ter um resultado entre 2 e 1250 onde até 250 será um risco muito pequeno, entre 251 e 500 um risco pequeno, entre 501 e 750 médio, 751 e 1000 grande e 1000 e 1250 elevado (BRASILIANO, 2005). 
Tabela 2 - Análise de riscos a partir do Método Mosler

\begin{tabular}{|c|c|c|c|c|c|c|c|c|c|c|c|c|c|}
\hline \multirow[b]{3}{*}{ ITEM } & \multirow[b]{3}{*}{ RISCOS } & \multirow{2}{*}{\multicolumn{6}{|c|}{$\begin{array}{c}\text { ANÁLISE DO } \\
\text { RISCO }\end{array}$}} & \multicolumn{5}{|c|}{ AVALIAÇÃO DO RISCO } & \multirow{3}{*}{$\begin{array}{l}\text { CLASSE DO } \\
\text { RISCO }\end{array}$} \\
\hline & & & & & & & & $\mathbf{I}$ & $\mathrm{D}$ & $\mathbf{M}$ & $\mathbf{P e}$ & Er & \\
\hline & & f & $\mathbf{s}$ & p & e & $\mathbf{P b}$ & If & fxs & pxe & $\mathrm{I}+\mathrm{D}$ & PbxIf & $\mathrm{MxPe}$ & \\
\hline 1 & Infraestrutura & 4 & 4 & 1 & 2 & 4 & 4 & 16 & 2 & 18 & 16 & 288 & Pequeno \\
\hline 2 & Incêndio & 3 & 4 & 4 & 2 & 3 & 5 & 12 & 8 & 20 & 15 & 300 & Pequeno \\
\hline 3 & Pragas & 3 & 3 & 2 & 2 & 1 & 3 & 9 & 4 & 13 & 3 & 39 & Muito pequeno \\
\hline 4 & Poluentes & 3 & 3 & 2 & 2 & 1 & 3 & 9 & 4 & 13 & 3 & 39 & Muito pequeno \\
\hline 5 & $\begin{array}{l}\text { Aparelhos } \\
\text { eletrônicos }\end{array}$ & 3 & 4 & 4 & 2 & 3 & 4 & 12 & 8 & 20 & 12 & 240 & Pequeno \\
\hline
\end{tabular}

Fonte: Dados da pesquisa (2019).

\subsubsection{Infraestrutura}

O primeiro aspecto analisado foi relacionado a infraestrutura do ambiente, onde neste tópico compreendeu-se tanto o espaço físico do arquivo, como os arredores, considerando aspectos prediais, que poderiam ser riscos potenciais ao arquivo da PROGEP. Nesse sentido, averiguou-se que, no tocante da infraestrutura existem alguns problemas potenciais como o surgimento de infiltrações ou problemas elétricos que levariam a quedas de energia. Isso justifica-se uma vez que o prédio é antigo e passou períodos sem reparos ou grandes melhorias estruturais.

Uma das formas que a equipe gestora do arquivo tem feito para evitar que tais problemas entre em evidência, é a contratação de empresas terceirizadas para a realização de alguns serviços preventivos na estrutura física, tanto do prédio como do arquivo. Estas revisões periódicas buscam verificar os aspectos físicos e estruturais, e quando necessário, as devidas correções.

Um dos pontos estruturais que se destacam enquanto positivo é a disponibilidade de materiais e aparelhos tecnológicos que facilitam o trabalho desta unidade de informação. $\mathrm{O}$ arquivo conta com uma central de ar condicionado, desumidificadores, estantes deslizantes, extintores, mobiliários apropriados para tratamento documental, dedetização programada e ambiente higienizado e climatizado.

Nesse sentido, para o aspecto infraestrutural dentro da unidade de informação, a probabilidade para o surgimento dos riscos não se mostrou acentuada. Percebeu-se que existe uma preocupação pela equipe do arquivo em evitar ocorrências, além de uma rotina de reparação 
periódica para que minimize os riscos que possam impactar de maneira direta ou indiretamente o acervo documental. Considerando-se isso, o risco estrutural é pequeno.

\subsubsection{Incêndio}

O segundo aspecto analisado foi relacionado ao risco de incêndio no arquivo. Esse é um risco onde as unidades de informação devem levar em consideração, visto que incêndios podem ocasionar danos irreparáveis ao acervo bibliográfico, o que configura em uma perda definitiva da documentação e da memória salvaguardas nessas organizações.

O risco de incêndio no arquivo estudado pode ocasionar perdas em diversos aspectos, a saber: nos documentos salvaguardados, no maquinário tecnológico (computadores, centrais de ar condicionado, desumidificadores) e nos equipamentos mobiliários (mesas, estantes, prateleiras). Spinelli e Pedersoli Júnior (2010) explicam que as causas de incêndios podem ser de origem interna ou externa, falhas em equipamentos eletroeletrônicos, incêndio criminoso, dentre outros.

Nesse sentido, a possibilidade de restauração de acervos documentais físicos, diante de um incêndio, é algo praticamente impossível. Logo, algumas práticas vêm sendo adotadas para minimizar esses riscos, como ter disponível em seu espaço físico e arredores extintores de incêndio. Um outro fator que poderia potencializar os cuidados no tocante do incêndio seria a utilização de sensores de fumaça, contudo tal aparato ainda não é utilizado por esta unidade de informação.

Além disso, o arquivo também operacionaliza uma considerável quantidade de processos documentais em formatos eletrônicos por meio do Sistema Eletrônico de Informações (SEI), o que diminui o volume de arquivos impressos. Motta e Silva (2020) ressaltam sobre a importância de investimentos em repositório digitais que possam tanto preservar a memória como também tornála acessível ao público.

No que tange a probabilidade de incêndio dentro da unidade de informação, este se mostrou um risco pequeno. $\mathrm{O}$ arquivo conta com equipamentos que possibilitem uma atuação diante de um incêndio, embora alguns materiais como sensores de fumaça, tornassem ainda menor esse risco. O impacto financeiro e a substituição no caso de incêndios são aspectos elevados, desse modo, é preciso que a equipe do arquivo tenha atenção especial aos equipamentos eletrônicos, para não sobrecarregar a rede elétrica. 


\subsubsection{Pragas}

As pragas são aspectos presentes nas unidades de informação e nem sempre visíveis, o que pode dificultar a identificação e a solução de problemas. São exemplos de pragas baratas, roedores, morcegos, aves, além de microorganismos que podem estar presentes nos documentos, como fungos. É fato que "a interação das pragas com os materiais do patrimônio podem causar, dependendo de sua vulnerabilidade, perfurações, perdas de partes, enfraquecimento estrutural, sujidades e manchas." (PEDERSOLI JÚNIOR, p.27, 2010).

Os colaboradores da unidade de informação em questão, realizam procedimentos de inspeção de pragas e outros roedores que possam significar algum risco para os documentos físicos e, para reforçar todas as normas de segurança, realizam a digitalização de alguns documentos deteriorados pelo tempo, como também alisamento que garantam a preservação desses documentos que são considerados mais frágeis. Outro fator importante está relacionado a equipe de limpeza, que realiza diariamente troca de lixo e a higienização do ambiente.

Deste modo, as pragas de um modo geral representam um risco muito baixo para o arquivo. Há um esforço pela equipe gestora em manter um ambiente limpo e livre de pragas, com medidas sanitárias de limpeza e higienização da unidade de informação. Existe ainda um preparo tecnológico com máquinas que possibilitam a digitalização do acervo documental, quando este mostrar-se danificado em decorrência ao surgimento de pragas.

\subsubsection{Poluentes}

Considera-se como poluentes aspectos internos e externos que podem causar danos ao acervo, como por exemplo: produtos de limpeza, tintas, líquidos, alimentos, usuários, produtos químicos como solventes e alvejantes, dentre outros que possam danificar e/ou poluir o acervo (PEDERSOLI JÚNIOR, 2010).

Sob o ponto de vista do risco por poluentes na unidade de informação, o local conta com poucos elementos ou substâncias tóxicas que possam danificar o acervo documental. São utilizados produtos químicos para realizar os procedimentos de restauração e conservação do documento, contudo, a unidade de informação conta com equipamentos de proteção individual (EPI), além de protocolos para garantir a segurança dos colaboradores e do acervo, de modo a evitar qualquer risco potencial envolvendo poluentes.

Esse protocolo internado é disseminado em toda unidade para que seja possível a manipulação segura dos elementos químicos que são utilizados para a restauração, preservação e 
conservação de documentos, além de evitar outros tipos de exposição como fungos e ácaros. Acresce-se ainda que, por ser um local fechado, existe pouco risco de poluição externa, sendo necessário a atenção para os cuidados e protocolos internos. Assim sendo, o risco de contaminação do acervo por poluentes no arquivo é algo muito pequeno.

\subsubsection{Aparelhos eletrônicos}

$\mathrm{Na}$ atual sociedade, um fator que reconfigurou as formas de trabalhar foram as tecnologias de informação e comunicação. Estas estão presentes em diversos âmbitos e nas mais diversas camadas sociais, facilitando atividades rotineiras, inclusive no âmbito do trabalho (AUTOR 1, 2019). Considerando-se isso, notou-se que o arquivo estudado tem tido esforços para a transformação digital, isto é, tem realizado processos de gestão documental e digitalização de documentos.

Nesse sentido, compreendeu-se que os aparelhos eletrônicos são fatores fundamentais para a realização dos trabalhos da unidade de informação e a falta de utilização destes, seja por problemas diversos, significaria uma perda de produtividade e um risco para o arquivo. Logo, buscou-se entender como se dava a importância desses aparelhos e quais atividades eles facilitam.

Analisou-se que os aparelhos eletrônicos como computadores e scanners são de suma importância para o mapeamento e digitalização da documentação arquivada, além de serem utilizados para acessar o SEI (Sistema Eletrônico de Informação). A perda de materiais eletrônicos, seja por motivos elétricos ou de obsolescência acarretaria um impacto significativo na instituição.

No entanto, a unidade de informação procura de maneira sistemática adequar esse impacto financeiro as contingências necessárias para assegurar que os equipamentos estejam em conformidade para o seu adequado funcionamento, possibilitando às pessoas a trabalharem melhor com essas ferramentas no intuito de propiciar um controle adequado dos documentos que são alocados dentro do arquivo.

A unidade de informação conta com uma diversidade de maquinário tecnológico para que o uso contínuo e necessário dos aparelhos eletrônicos não seja interrompido. É preciso atenção a qualidade técnica das máquinas e, ocasionalmente, trocá-las de modo a evitar a obsolescência, além de garantir a preservação digital com processo de migração, diversidade e economia (ROSENTHAL et al., 2005 apud TAVARES; SIEBRA; LIMA, 2019). Como tais cuidados têm sido observados e devidamente cuidados, o risco envolvendo os aparelhos eletrônicos é pequeno. 


\section{CONSIDERAÇÕES FINAIS}

Diante dos estudos realizados, foram observados que a gestão de riscos vem ganhando notoriedade nas discussões acadêmicas e científicas, e que esta temática possibilitou consideráveis contribuições no tocante da ciência da informação, biblioteconomia, museologia e áreas afins, visto que a partir da gestão de riscos pôde-se elaborar políticas para contingenciar riscos no patrimônio memorial documental e histórico das unidades de informação.

A importância da gestão de riscos ao longo desse trabalho, destacou-se sobretudo no âmbito arquivístico, uma vez que essas unidades de informação têm papel fundamental para conservação, preservação e disseminação dos patrimônios documentais. Nesse ínterim, é fundamental que as universidades, por meio dos cursos de graduação, deem a devida atenção a esse tema e desenvolvam, dentro do plano político pedagógico dos cursos, disciplinas voltadas à gestão e gerenciamento de riscos.

Nesse sentido, a gestão de riscos já é uma realidade no contexto da Universidade Federal do Ceará, contudo, os conhecimentos e percepções dos funcionários desta instituição ainda se encontram em fase embrionária. É fundamental o fortalecimento desses conhecimentos por meio de ações institucionais que capacitem os servidores para atuar preventivamente e de forma efetiva frente a presença de riscos nos ambientes de trabalho.

\section{REFERÊNCIAS}

ASSOCIAÇÃO BRASILEIRA DE NORMAS TÉCNICAS. NBR ISO 31000:2009 - Gestão de Riscos: Princípios e Diretrizes. Rio de Janeiro, ABNT, 2009.

ALMEIDA, M. C. Auditoria: um curso moderno e completo. 6. ed. São Paulo: Atlas, 2003.

AUTOR 1, 2019

BARALDI, P. Gerenciamento de riscos empresariais: a gestão de oportunidades, a avaliação de riscos e a criação de controles internos nas decisões empresariais. 2. ed. Rio de Janeiro: Elsevier, 2005.

BRASILIANO, A. C. R.. Análise de riscos. Revista Eletrônica Brasiliano \& Associados, São Paulo, n. 20, set./out. 2005. Disponível em:

https://docs.wixstatic.com/ugd/fbc826_56f9c26a375a42f39f4c2f713d0ca48e.pdf. Acesso em: 01 dez. 2020.

BRASIL. Tribunal de Contas da União. Referencial básico de gestão de riscos. Tribunal de Contas da União. - Brasília: TCU, Secretaria Geral de Controle Externo, 2018. 154 p.

BRITO, O. S. Gestão de riscos: uma abordagem orientada a riscos operacionais. São Paulo: Saraiva, 2002.

BRÜSEKE, F. J. Risco e contingência. Revista Brasileira de Ciências Sociais, v. 22, n. 63, p. 69-80, 2007. 
COCURULLO, A. Gestão de riscos corporativos: riscos alinhados com algumas ferramentas de gestão: um estudo de caso no setor de celulose e papel. São Paulo: Scortecci, 2002.

COOPER, D.R.; SCHINDLER, P.S. Métodos de Pesquisa em Administração.7. ed. Porto Alegre: Bookman, 2003.

DIAS, A. A. ética profissional e memória no arquivo. Revista Fontes Documentais, v. 1, n. 1, p. 19-31, 2018.

GIL, A. C. Como elaborar projetos de pesquisa. 5 ed. São Paulo: Editora Atlas, 2010. 184 p.

HOLLÓS, A. C.; PEDERSOLI Jr., J. L. Gerenciamento de riscos: uma abordagem interdisciplinar.

PontodeAcesso, v. 3, n. 1, p. 72-81, 2009.

LIMA, C. A.; FREIRE, S. C. Gestão de riscos em acervos bibliográficos: análise de riscos na Biblioteca Francisca Keller. Memória e Informação, v. 3, n. 2, p. 118-136, 2019.

ACEDO, S. M. S.; ORTEGA, C. D. Unidades de informação: termos e características para uma diversidade de ambientes de informação. Em questão, v. 25, n. 2, p. 326-347, 2019.

MARCONI, M. A.; LAKATOS, E. M. Técnicas de pesquisa. 7 ed. São Paulo: Editora Atlas, 2010. 277 p.

MOTTA, F. M. V.; SILVA, R. A. R. A adoção de tecnologias digitais na reconstrução do patrimônio: relato da experiência do museu nacional, Brasil. Informação \& Sociedade: Estudos, v. 30, n. 2, 2020.

NOBRE, L. C.; SOUZA, O. Museu de Arte e Cultura do Ceará: uma análise dos riscos baseados em um modelo integrado dos fluxos de informação dos métodos Fine e Mosler. Informação em Pauta, v. 3, n. 1, p. 26-51, 2018.

PEREIRA, A. M. S. M. Gerenciamento de riscos: do planejamento à execução. Rio de Janeiro: Arquivo Nacional, 2019.

PRADO, E. V. Et al. Sistemas de informações para gerenciamento de riscos corporativos em controladoria: um estudo bibliométrico na base de dados scopus. Perspectivas em Gestão \& Conhecimento, v. 7, n. 1, p. 191-211, 2017.

SALLES JÚNIOR, C. A. C.; et al. Gerenciamento de riscos em projetos. Rio de Janeiro: Editora FGV, 2006.

SANTOS, P. S. M.. Gestão de riscos empresariais. Osasco, SP: Novo Século Editora, 2002.

SILVA, À. C.; NASCIMENTO, G. B. Gerenciamento de riscos no acervo do arquivo da Fundação Casa de José Américo na cidade de João Pessoa - PB. Archeion Online, v. 3, n. 11, p. 25-44, 2015.

SILVA, D. E. L. S.; ARAÚJO, S. L. A.; CAMPELLO, L. O. S. Gestão de riscos o método do COSO aplicado à gestão de uma unidade de informação. RDBCI, v.18, p. 1-21, 2020

SPINELLI, J.; PEDERSOLI JÚNIOR, J. L.. Biblioteca Nacional: plano de gerenciamento de riscos: salvaguarda \& emergência. Rio de Janeiro: Fundação Biblioteca Nacional, 2010.

TAVARES, A. L. L.; SIEBRA, S. A.; GALINDO, M. L. O gerenciamento de risco no ciclo da curadoria digital. Archeion Online, v. 6, n. 2, p. 83-104, 2019.

VENEZIA A. G.; ONO, R. Aplicação de método de análise de risco visando o aprimoramento da segurança contra incêndio no decorrer do processo de projeto de hospitais de grande porte. Gestão de Tecnologia de Projetos, v. 8, n. 2, p. 89-103, 2013. 